\title{
LIFE HISTORIES OFFER A CLUE TO THE FUTURE OF INFECTIOUS DISEASE ON CORAL REEFS
}

\author{
L. YAKOB ${ }^{\otimes 1}$ and P. J. MUMBY ${ }^{2}$
}

(Received 24 July, 2012; revised 15 November, 2012; first published online 4 February, 2013)

\begin{abstract}
Increased frequency and severity of stressors associated with climate change are drastically altering ecosystems. Caribbean coral reefs differ markedly from just 30 years ago, with much restructuring attributable to infectious disease outbreaks. Using a classic epidemiological approach, we demonstrate how density-dependent demographic rates serve as a mechanism for intrinsic coral resilience to population perturbations arising from disturbances such as disease. We explore the impact of allowing infection status to influence demographic rates and ascertain outbreak thresholds that are corroborated by epizootic patterns observed in the field. We discuss how our threshold calculations may provide metrics of coral epizootic early warning systems. Integrating our infection model with equations describing the interspecific competition for space between coral and macroalgae, we provide new mechanistic understanding of the influence that coral life history dynamism and infectious disease have on the changing face of these threatened ecosystems.
\end{abstract}

2010 Mathematics subject classification: 92D25.

Keywords and phrases: transmission dynamics, early warning systems, population dynamics.

\section{Introduction}

The impacts of climate change on ecosystems are as diverse as they are widespread [35]. Although the effects of climate-associated stressors have been largely deleterious, a minority of ecological studies have documented mitigating adaptations. These fall into three general categories: geographical range shifts [45], phenotypic plasticity [9] or evolution [44]. Despite evidence of more polar distributions [19] and thermal acclimatization [8], the scope for adequate genetic or epigenetic adaptation in coral is uncertain on ecological time scales [2].

\footnotetext{
${ }^{1}$ School of Population Health, University of Queensland, Herston, QLD 4006, Australia; e-mail: laith.yakob@uq.edu.au.

${ }^{2}$ School of Biological Sciences, University of Queensland, St. Lucia, QLD 4072, Australia.

(C) Australian Mathematical Society 2013, Serial-fee code 1446-1811/2013 \$16.00
} 
One of the most profoundly impacted coral reef regions is the Caribbean [23]. Disease has been a principle cause of Caribbean coral decline and is increasingly considered to be a key stressor of global coral reefs [6]. The brunt of coral epizootics has been experienced by Acropora and Montastraea spp. in the Caribbean [17, 27]. These massive reef building corals are characterized by great longevity and rare recruitment events [14], with the former trait only necessitating the latter trait for persistence. Susceptibility to infection has been attributed to physiological predisposing factors [11] and/or environmental stressors [6], but the link between life history traits and disease transmission [47] and the influence of infection status on demography and interspecific interactions may also be important.

Disease has indirect as well as direct effects on coral population persistence. In addition to partial and whole-colony mortality associated with infection, chronic stressors weaken the ability of coral to compete with macroalgae for space [43] and might also compromise fecundity by reducing effective colony size [41] or increasing stress [16]. We begin by extending our previously published coral population infection model [47] to allow for recovery from infection [37, 40]. We then incorporate the infection model into a set of equations describing the interspecific competition for space between coral and macroalgae. In doing so, we explore new mechanisms of influence between coral life history dynamism and infectious disease, and their combined impact on coral reef ecosystems.

\section{Methods}

2.1. Disease spread within a coral population Coral, denoted here by $C$, consists of colonies that are susceptible $(S)$, infected $(I)$ or recovered $(R)$ (hence, $C=S+$ $I+R)$. For undisturbed populations of large reef builders, there is negative skewing in the colony size structure [10], meaning that the population is dominated by large coral colonies. Following disturbances, coral coverage is reduced and colony size structure becomes more positively skewed [26]. Recruitment rates increase as more free space is made available [13] and average colony mortality rates also increase due to a greater proportion of smaller colonies [25]. This life history dynamism can easily be incorporated into the classic susceptible-infected-recovered framework:

$$
\begin{aligned}
\frac{d S}{d t} & =(S+I \theta+R) r\left(1-\frac{C}{K}\right)-S \mu_{1}\left(1-\frac{C}{K}\right)-\beta S I, \\
\frac{d I}{d t} & =\beta S I-I\left(\mu_{1}\left(1-\frac{C}{K}\right)+\mu_{2}+\epsilon\right), \\
\frac{d R}{d t} & =\epsilon I-R \mu_{1}\left(1-\frac{C}{K}\right) .
\end{aligned}
$$

Here $r$ and $\mu_{1}$ are coral population growth and mortality, respectively, $\mu_{2}$ is the additional mortality associated with infection, $\beta$ is the transmission rate and $\epsilon$ is the rate of recovery from infection. Mass action in pathogen transmission is assumed because of the super-connectivity of pathogens within marine systems [28]. We let $K$ 
denote the carrying capacity, the level of coral coverage for which new recruitment and natural mortality are exactly in balance. Both population growth and mortality are higher when colonies are smaller and more scarce: they are "inversely density dependent" $[13,25]$. We have previously reported a susceptible-infected model including coral population dynamics [47], and so the first model of the current study extends upon this previous work by allowing for coral recovery from infection, and by allowing an adjusted population growth rate of infected colonies. Letting $\theta$ denote the recruitment ability of infected coral relative to uninfected coral $(0 \leq \theta \leq 1)$, we explore the dynamical properties of reduced coral recruitment associated with infection.

2.2. Interspecific competition between coral and macroalgae Not only does coral compete with other coral, it also competes with macroalgae for space. The current trend in coral reef deterioration has often been accompanied by phase shifts from coral-rich to algal-rich states [17, 22, 29]. Disease is expected to have an important impact on benthic community dynamics [46], but this notion has not been studied in detail. Combining our infection model with the coral-macroalgal model of Mumby et al. [32], we derive the following differential equations:

$$
\begin{aligned}
\frac{d S}{d t} & =r C T+\omega R-\beta S I-S\left(\mu_{1}(1-C)+a_{1} M\right), \\
\frac{d I}{d t} & =\beta S I-I\left(\mu_{1}(1-C)+\mu_{2}+a_{2} M+\epsilon\right), \\
\frac{d R}{d t} & =\epsilon I-R\left(\mu_{1}(1-C)+a_{1} M+\omega\right), \\
\frac{d M}{d t} & =M\left(a_{1}(S+R)+a_{2} I+\gamma T\right)-\frac{g M}{M+T} .
\end{aligned}
$$

Here macroalgae $M$ overgrow turf $T$ at rate $\gamma$, and can overgrow uninfected and infected coral at respective rates $a_{1}$ and $a_{2}$. Turf can be calculated simply as $T=$ $1-(M+C)$ under the assumption of a complete coverage carrying capacity $(K=1)$. In this way, turf represents all habitable space that is not occupied by either macroalgae or coral [32]. It is reasonable to assume that coral's competitiveness for space is compromised by infection since other chronic stresses reduce coral growth rate [43]; hence $a_{2} \geq a_{1}$. Macroalgae are depleted through grazing $g$ by herbivores. Susceptible coral is replenished either through recruitment over turf or through loss of immunity $\omega$ from the recovered class. Therefore, the first model (2.1)-(2.3) is a special case of the second model (2.4)-(2.7) whereby the first model is regained when $K$ is explicit, $M=0, \theta=1$ and $\omega=0$. The second model is used to investigate the importance of infectious disease and inversely density-dependent coral population dynamics in coral-macroalgal antagonism.

\section{Results}

3.1. Disease thresholds and coral population dynamics From the model described by equations (2.1)-(2.3), the critical threshold population density for an infection to 


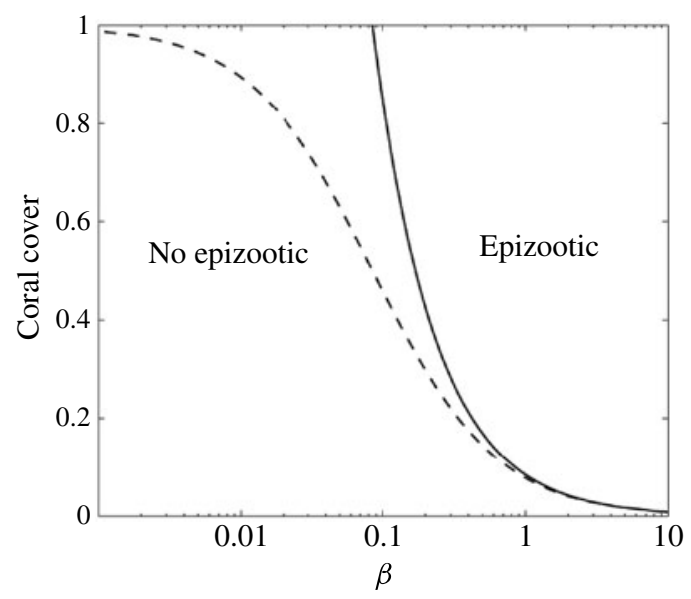

FIGURE 1. Epizootic threshold conditions as a function of coral cover $C$ and disease transmission coefficient $\beta$, from the model (2.1)-(2.3). The basic reproductive number is $\beta C /\left(\mu_{1}(1-(C / K))+\right.$ $\left.\mu_{2}+\epsilon\right)$ and $\beta C /\left(\mu_{1}+\mu_{2}+\epsilon\right)$ for inversely density-dependent and density-independent coral mortality, respectively (density-independent mortality is achieved simply by reducing $\mu_{1}\left(1-(C / K)\right.$ ) to $\left.\mu_{1}\right)$. Inversely density-dependent mortality (dashed line) predisposes coral to epizootics (density-independent mortality denoted by solid line). Parameter values are $r=0.25, \mu_{1}=0.2125, \mu_{2}=0.05, \epsilon=0$ and $\theta=1$.

spread is calculated as follows:

$$
S>\frac{\mu_{1}}{\beta}\left(1-\frac{C}{K}\right)+\frac{\mu_{2}+\epsilon}{\beta} .
$$

Hence, the closer the population is to carrying capacity, the more vulnerable it becomes to an outbreak. Epizootic thresholds are illustrated in Figure 1, which shows that inclusion of inversely density-dependent coral mortality actually facilitates disease outbreaks. Inversely density-dependent natural coral mortality, therefore, may explain the widely observed propensity for disease to spread among larger colonies [5] as well as the heightened susceptibility of regions with high coral coverage to outbreaks $[6,36]$. Intuitively, recovery from infection or infection-induced mortality hampers disease spread. Similarly, loss of immunity $(\omega>0)$ replenishes the pool of susceptible coral, enhancing disease spread. Under the assumption that prior to an epizootic, the prevalence of infected coral is very low, the initially susceptible class of coral is approximated by the total coral population, and the critical coral coverage for disease spread can be rewritten as

$$
C>\frac{K\left(\mu_{1}+\mu_{2}+\epsilon\right)}{\beta K+\mu_{1}} .
$$

Trajectory switches arise when coral density increases and exceeds the threshold epizootic conditions. Birth and death rates decrease with increasing average coral colony size. This leads to booms followed by busts in the coral population. Example 


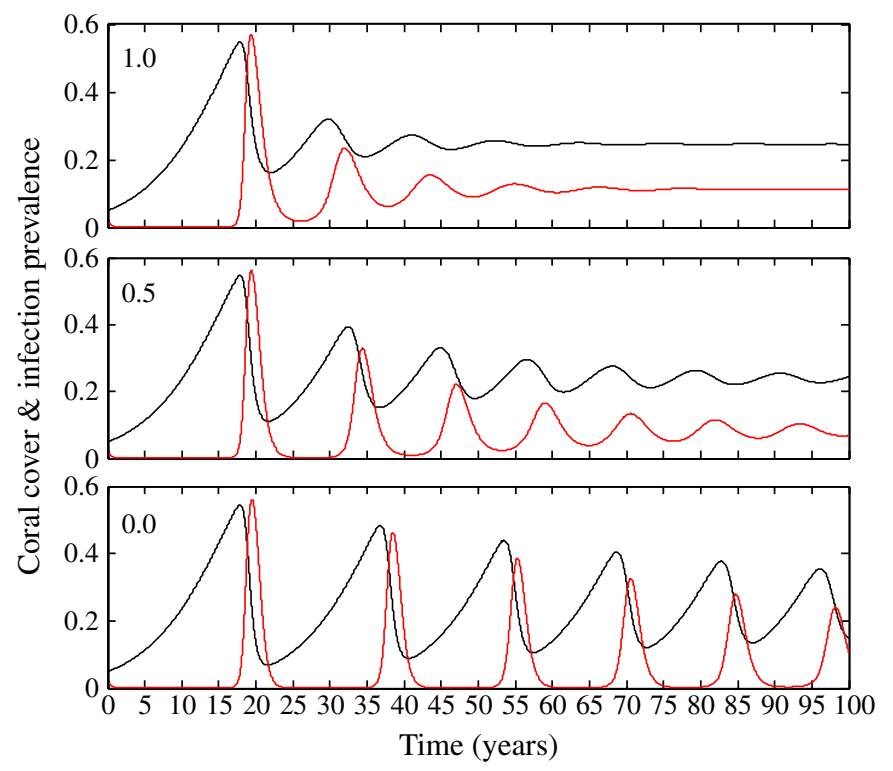

FIgURE 2. Temporal dynamics of coral cover $(S$, black) and infection prevalence $(I / C$, red) under different abilities of infected coral to recruit, represented by $\theta$ values in top-left of panels: 1.0 denotes no difference from uninfected coral, 0.5 is a halved ability and 0.0 a complete inability to recruit. Trajectory switches in infection spread occur once threshold coral coverage is exceeded. Parameter values are $r=0.25$, $\mu_{1}=0.2125, \mu_{2}=0.05, \beta=1$ and $\epsilon=0$, for the model (2.1)-(2.3). (Colour available online.)

temporal dynamics are displayed in Figure 2, which also demonstrates the effects of reduced fecundity associated with infection. Single host infections are not expected to cause extinction [1]. Instead, the coral population experiences booms followed by busts once the epizootic threshold is breached, the severity of which is exacerbated by the reduced ability of infected colonies to recruit (Figure 2). The overall results are dampened oscillations of infection until the coral population stabilizes below the epizootic threshold.

3.2. Climate change and the competitive exclusion of coral When coralmacroalgal interactions are included (equations (2.4)-(2.7)), one species competitively excludes the other, in agreement with Mumby et al. [32]. Setting our parameter values to those of Mumby et al. [32], we determined the impact that infectious disease and density-dependent coral mortality have on the thresholds for exclusion (Figure 3). Incorporating infection into the model of antagonism had intuitive results: it shifted the exclusion threshold in favour of a macroalgal-dominant state, and this shift was exacerbated by allowing macroalgae to overgrow infected coral more effectively $\left(a_{2} \geq a_{1}\right)$. Conversely, incorporating inversely density-dependent coral mortality demonstrated enhanced coral resilience by increasing the tendency for macroalgal exclusion. Therefore, heightened coral population turnover (for example, increased coral recruitment) and infectious disease (for example, decreased recruitment and 


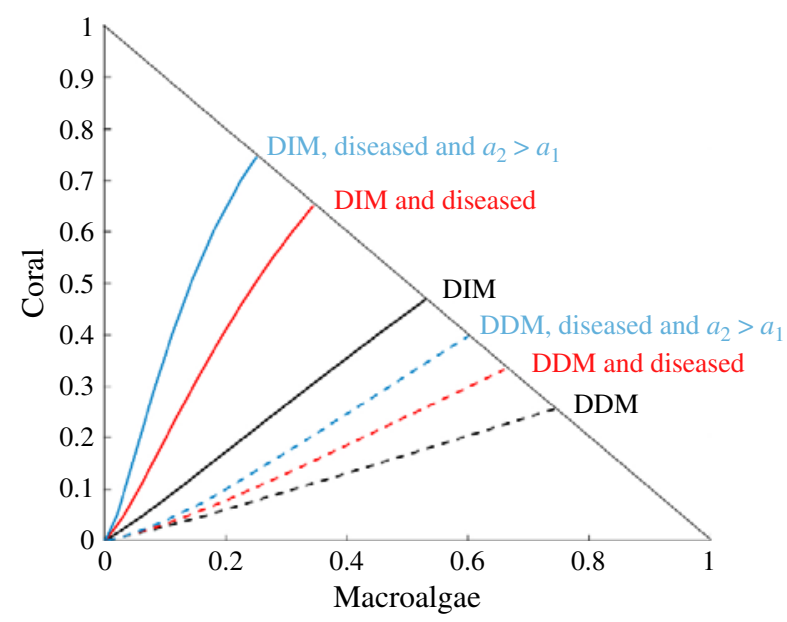

FIGURE 3. Effects of infectious disease and inversely density-dependent coral mortality on thresholds for coral-macroalgal competitive exclusion. Here "DDM" means inversely density-dependent mortality and "DIM" means density-independent mortality; $a_{2}>a_{1}$ denotes enhanced ability for macroalgae to overgrow infected coral (by a factor of 2). The areas above and to the left of the thresholds represent initial conditions that favour coral dominance. For comparative purposes, all other parameters pertaining to interspecific competition are set to those of Mumby et al. [32]: $r=1.0, \mu_{1}=0.44, g=0.3, \gamma=0.8$, $a_{1}=0.1, \mu_{2}=0.05, \beta=1, \epsilon=0$ and $\omega=0$.

increased mortality) that may result from climate change [6, 47] have antagonizing effects on the interspecific interactions between coral and macroalgae.

\section{Discussion}

Phase shifts from coral- to macroalgal-rich states have been documented in many Caribbean reef systems [17, 22, 29] and have arisen because of a decline in system resilience combined with unprecedented mortality visited upon coral through disease, hurricanes and bleaching [7, 20,33, 39, 42]. Of the consortium of factors negatively affecting coral reefs, infectious disease has arguably received the least research effort despite current opinion of its future impact on coral reefs [6]. Using the classic susceptible-infected-recovered approach, we have demonstrated threshold conditions for coral epizootics and examined the influence of infectious disease on coral reef dynamics.

Links between coral colony size and life history traits have been studied for decades [24, 31]. Long-lived species, such as the major reef builders, are typically believed to have "slow" life histories. Populations with slow growth and high survival are understood to have constrained resilience through a delayed reaction to perturbation [15, 34]. However, life history traits of coral are dynamic. Coral demographics are inversely density-dependent [21], thereby providing a mechanism for populations to recover more rapidly from downward perturbations [4]. Following epizootics, disease resistance has been observed in the surviving coral colonies [38]. 
While this is normally attributed to adaptive immunological responses [37, 40], we suggest that there may be an additional mechanism. The positively skewed colony size structure following the epizootic [26] provides natural coral resistance through the accelerated population turnover rate. Although higher population turnover rates are understood classically to attenuate disease outbreaks [12], the significance of this relationship has until recently been overlooked in the context of coral reef epizoology [47].

Of concern are findings of Bak and Meesters [3] and Meesters et al. [30] which demonstrate precisely the opposite response: a negative skewing of post-disturbance colonies under conditions where new recruitment is inhibited. We recommend maintaining close monitoring of these types of reef systems as they may represent populations that are primed for epizootics in addition to having little prospect for recovery. Our simple analysis suggests that this priming of coral populations can occur several years before detectable increases in disease prevalence, demonstrating potential for our threshold calculations to contribute towards the development of an early warning system for coral reef disease outbreaks. Better understanding of the coral reef infection dynamics will allow for more quantitative, species-specific calculations of critical coverage levels. It is important to consider the health of coral in the context of the wider biological community. Therefore, we have examined the interplay between coral disease infection and interspecific competition with macroalgae. Our results show that infectious disease may shift the threshold for competitive exclusion in favour of macroalgae. Enhanced ability of macroalgae to overgrow infected coral and reduced recruitment of infected colonies further biased the system towards macroalgal dominance. The complexity of the system makes it difficult to gauge the relative contribution that disease made to the massive and rapid coral decline within the Caribbean during the late 1970s to 1980s. Like all models, we acknowledge the oversimplification represented by our mathematical description of this complex system. Disease is almost definitely linked with climate [6] and phase shifts in community structure are also driven by a loss of system resilience [32]. However, by linking life history traits with colony size structure, we elucidate an additional mechanism of natural coral resistance. Field studies to corroborate our hypothesized interaction between disease and coral-macroalgal antagonism represent a priority research area as they will be paramount for making accurate projections of anthropogenic effects on the fate of coral reef systems.

Reduced average colony size and ameliorated intraspecific competition following disturbance would be expected to result in increased population turnover for any given coral species. However, such changes in turnover will likely be accompanied by a shift in the composition of the coral assemblage. In the Caribbean, for example, the long generation times and limited recruitment of many large-bodied broadcast spawners (for example, Montastraea annularis) have led to population depletion and increased dominance of diminutive brooding species, such as Agaricia agaricites [18]. While a more rapid population turnover of the new assemblage may confer enhanced resilience, such switches in species composition are unlikely to be desirable. Not only 
does this switch reduce species diversity, but the functioning of such assemblages, such as providing habitat for a diverse fish fauna, will likely be diminished. Thus, a more comprehensive analysis of disease-mediated impacts will have to consider how changes in population size and assemblage composition affect the robustness of the community to sustain individual ecosystem services.

\section{References}

[1] R. M. Anderson, R. M. May, K. Joysey, D. Mollison, G. R. Conway, R. Cartwell, H. V. Thompson and B. Dixon, "The invasion, persistence and spread of infectious diseases within animal and plant communities [and discussion]”, Philos. Trans. R. Soc. Lond. B 314 (1986) 533-570; doi:10.1098/rstb.1986.0072.

[2] A. H. Baird, V. R. Cumbo, W. Leggat and M. Rodriguez-Lanetty, "Fidelity and flexibility in coral symbioses", Mar. Ecol. Prog. Ser. 347 (2007) 307-309; doi:10.3354/meps07220.

[3] R. P. M. Bak and E. H. Meesters, "Population structure as a response of coral communities to global change", Amer. Zool. 39 (1999) 56-65; doi:10.1093/icb/39.1.56.

[4] B. W. Brook and C. J. A. Bradshaw, "Strength of evidence for density dependence in abundance time series of 1198 species", Ecology 87 (2006) 1445-1451; doi:10.1890/0012-9658(2006)87[1445:SOEFDD2.0.CO;2].

[5] A. W. Bruckner and R. J. Bruckner, "Condition of coral reefs off less developed coastlines of Curaçao (Part 1: Stony corals and algae)”, Atoll. Res. Bull. 496 (2003) 370-393; http://www.sil.si.edu/digitalcollections/atollresearchbulletin/issues/00496.21x.pdf.

[6] J. F. Bruno, E. R. Selig, K. S. Casey, C. A. Page, B. L. Willis, C. D. Harvell, H. Sweatman and A. M. Melendy, "Thermal stress and coral cover as drivers of coral disease outbreaks", PLoS Biol. 5 (2007) e124; doi:10.1371/journal.pbio.0050124.

[7] J. Bythell and C. Sheppard, "Mass mortality of Caribbean shallow corals", Mar. Pollut. Bull. 26 (1993) 296-297; doi:10.1016/0025-326X(93)90569-6.

[8] K. D. Castillo and B. S. T. Helmuth, "Influence of thermal history on the response of Montastraea annularis to short-term temperature exposure", Mar. Biol. 148 (2005) 261-270; doi:10.1007/s00227-005-0046-X.

[9] A. Charmantier, R. H. McCleery, L. R. Cole, C. Perrins, L. E. B. Kruuk and B. C. Sheldon, "Adaptive phenotypic plasticity in response to climate change in a wild bird population", Science 320 (2008) 800-803; doi:10.1126/science.1157174.

[10] M. W. Colgan, "Coral reef recovery on Guam (Micronesia) after catastrophic predation by Acanthaster planci”, Ecology 68 (1987) 1592-1605; doi:10.2307/1939851.

[11] M. Díaz and J. Madin, "Macroecological relationships between coral species' traits and disease potential", Coral Reefs 30 (2011) 73-84; doi:10.1007/s00338-010-0668-4.

[12] O. Diekmann and J. A. P. Heesterbeck, Mathematical epidemiology of infectious diseases: model building, analysis and interpretation (Wiley, New York, 2002).

[13] P. Edmunds, "Recruitment of scleractinians onto the skeletons of corals killed by black band disease", Coral Reefs 19 (2000) 69-74; doi:10.1007/s003380050229.

[14] P. J. Edmunds and R. Elahi, "The demographics of a 15-year decline in cover of the Caribbean reef coral Montastraea annularis", Ecol. Monogr. 77 (2007) 3-18; doi:10.1890/05-1081.

[15] D. A. Fordham, A. Georges and B. W. Brook, "Experimental evidence for density-dependent responses to mortality of snake-necked turtles", Oecologia 159 (2008) 271-281; doi:10.1007/s00442-008-1217-5.

[16] N. L. Foster, I. B. Baums and P. J. Mumby, "Sexual vs. asexual reproduction in an ecosystem engineer: the massive coral Montastraea annularis", J. Anim. Ecol. 76 (2007) 384-391; doi:10.1111/j.1365-2656.2006.01207.x.

[17] T. A. Gardner, I. M. Côté, J. A. Gill, A. Grant and A. R. Watkinson, "Long-term region-wide declines in Caribbean corals", Science 301 (2003) 958-960; doi:10.1126/science.1086050. 
[18] D. H. Green, P. J. Edmunds and R. C. Carpenter, "Increasing relative abundance of Porites astreoides on Caribbean reefs mediated by an overall decline in coral cover", Mar. Ecol. Prog. Ser. 359 (2008) 1-10; doi:10.3354/meps07454.

[19] B. J. Greenstein and J. M. Pandolfi, "Escaping the heat: range shifts of reef coral taxa in coastal Western Australia", Global Change Biol. 14 (2008) 513-528; doi:10.1111/j.1365-2486.2007.01506.x.

[20] C. D. Harvell et al., "Emerging marine diseases-climate links and anthropogenic factors", Science 285 (1999) 1505-1510; doi:10.1126/science.285.5433.1505.

[21] T. P. Hughes, "Life histories and population dynamics of early successional corals", Proc. 5th Internat. Coral Reef Congress 4 (1985) 101-106;

http://www.reefbase.org/download/download.aspx?type=1\&docid=10023.

[22] T. P. Hughes, "Catastrophes, phase shifts, and large-scale degradation of a Caribbean coral reef", Science 265 (1994) 1547-1551; doi:10.1126/science.265.5178.1547.

[23] T. P. Hughes et al., "Climate change, human impacts, and the resilience of coral reefs", Science 301 (2003) 929-933; doi:10.1126/science.1085046.

[24] T. P. Hughes and J. B. C. Jackson, "Do corals lie about their age? Some demographic consequences of partial mortality, fission, and fusion", Science 209 (1980) 713-715; doi:10.1126/science.209.4457.713.

[25] T. P. Hughes and J. B. C. Jackson, "Population dynamics and life histories of foliaceous corals", Ecol. Monogr. 55 (1985) 141-166; doi:10.2307/1942555.

[26] T. P. Hughes and J. E. Tanner, "Recruitment failure, life histories, and long-term decline of Caribbean corals", Ecology 81 (2000) 2250-2263; doi:10.1890/0012-9658(2000)081[2250:RFLHAL]2.0.CO;2.

[27] N. Knowlton, "The future of coral reefs", Proc. Natl. Acad. Sci. 98 (2001) 5419-5425; doi:10.1073/pnas.091092998.

[28] H. McCallum, D. Harvell and A. Dobson, "Rates of spread of marine pathogens", Ecol. Lett. 6 (2003) 1062-1067; doi:10.1046/j.1461-0248.2003.00545.x.

[29] T. R. McClanahan and N. A. Muthiga, "An ecological shift in a remote coral atoll of Belize over 25 years", Environ. Conserv. 25 (1998) 122-130; doi:10.1017/S0376892998000174.

[30] E. H. Meesters, M. Hilterman, E. Kardinaal, M. Keetman, M. deVries and R. P. M. Bak, "Colony size-frequency distributions of scleractinian coral populations: spatial and interspecific variation", Mar. Ecol. Prog. Ser. 209 (2001) 43-54; doi:10.3354/meps209043.

[31] E. H. Meesters, I. Wesseling and R. P. M. Bak, "Coral colony tissue damage in six species of reefbuilding corals: Partial mortality in relation with depth and surface area", J. Sea Res. 37 (1997) 131-144; doi:10.1016/S1385-1101(96)00004-4.

[32] P. J. Mumby, A. Hastings and H. J. Edwards, "Thresholds and the resilience of Caribbean coral reefs", Nature 450 (2007) 98-101; doi:10.1038/nature06252.

[33] P. J. Mumby and R. S. Steneck, "Coral reef management and conservation in light of rapidly evolving ecological paradigms", Trends Ecol. Evol. 23 (2008) 555-563; doi:10.1016/j.tree.2008.06.011.

[34] J. A. Musick (ed.) Life in the slow lane: ecology and conservation of long-lived marine animals, Volume 23 of American Fisheries Society Symposium (American Fisheries Society, Bethesda, MD, 1999).

[35] C. Parmesan and G. Yohe, "A globally coherent fingerprint of climate change impacts across natural systems", Nature 421 (2003) 37-42; doi:10.1038/nature01286.

[36] L. J. Raymundo, A. R. Halford, A. P. Maypa and A. M. Kerr, "Functionally diverse reef-fish communities ameliorate coral disease", Proc. Natl. Acad. Sci. 106 (2009) 17067-17070; doi:10.1073/pnas.0900365106.

[37] K. C. Reed, E. M. Muller and R. van Woesik, "Coral immunology and resistance to disease", Dis. Aquat. Organ. 90 (2010) 85-92; doi:10.3354/dao02213.

[38] L. L. Richardson and R. B. Aronson, "Infectious diseases of reef corals", Proc. 9th Internat. Coral Reef Symp. 2 (2000) 1225-1231; http://www.reefbase.org/download/download.aspx?type=1\&docid=11799. 
[39] C. Rogers, "Coral bleaching and disease should not be underestimated as causes of Caribbean coral reef decline”, Proc. R. Soc. Lond. B 276 (2009) 197-198; doi:10.1098/rspb.2008.0606.

[40] E. Rosenberg, O. Koren, L. Reshef, R. Efrony and I. Zilber-Rosenberg, "The role of microorganisms in coral health, disease and evolution", Nature Rev. Microbiol. 5 (2007) 355-362; doi:10.1038/nrmicro1635.

[41] K. Soong, "Colony size as a species character in massive reef corals", Coral Reefs 12 (1993) 77-83; doi:10.1007/BF00302106.

[42] R. S. Steneck, "Is herbivore loss more damaging to reefs than hurricanes? Case studies from two Caribbean reef systems (1978-1988)", Proc. Colloq. Global Aspects of Coral Reefs: Health, Hazards, and History (1994) 220-226.

[43] J. E. Tanner, "Competition between scleractinian corals and macroalgae: an experimental investigation of coral growth, survival and reproduction", J. Exp. Mar. Biol. Ecol. 190 (1995) 151-168; doi:10.1016/0022-0981(95)00027-O.

[44] C. Thomas, "Recent evolutionary effects of climate change", in: Climate change and biodiversity (eds T. Lovejoy and L. Hannah), (Yale University Press, New Haven, CT, 2005), 75-90.

[45] G.-R. Walther, E. Post, P. Convey, A. Menzel, C. Parmesan, T. J. C. Beebee, J.-M. Fromentin, O. Hoegh-Guldberg and F. Bairlein, "Ecological responses to recent climate change", Nature 416 (2002) 389-395; doi:10.1038/416389a.

[46] E. Weil and A. Cróquer, "Spatial variability in distribution and prevalence of Caribbean scleractinian coral and octocoral diseases. I. Community-level analysis", Dis. Aquat. Organ. 83 (2009) 195-208; doi:10.3354/dao02011.

[47] L. Yakob and P. J. Mumby, "Climate change induces demographic resistance to disease in novel coral assemblages", Proc. Natl. Acad. Sci. 108 (2011) 1967-1969;

doi:10.1073/pnas.1015443108. 